\title{
O RECONHECIMENTO, ENTRE A JUSTIÇA E A IDENTIDADE'
}

\author{
PATRÍCIA MATTOS
}

Axel Honneth e Nancy Fraser, junto com Charles Taylor, são os principais autores que procuram retrabalhar, cada um a seu modo, o tema do reconhecimento como sendo central para uma teoria crítica da sociedade contemporânea. É possível notar uma íntima relação de influência entre o trabalho desses eminentes e influentes pensadores no debate contemporâneo. Ao mesmo tempo, também, é possível detectar tanto ênfases e pontos de partida distintos, por um lado, como também uma certa divisão do trabalho, por outro. Pretendo, neste ensaio, discutir o recente debate entre Honneth e Fraser ${ }^{2}$, cujo ponto central é precisamente determinar o alcance e os limites da perspectiva do reconhecimento para a análise das modernas sociedades do Ocidente. Fraser e Honneth discutem os principais pontos envolvidos na teoria do reconhecimento, suas fontes, as tematizações, filosófica e política, a construção de uma teoria social e os pressupostos para se pensar em uma teoria da Justiça. Ambos desejam colocar a categoria do reconhecimento como central para a reconstrução de um pensamento crítico, pretendem estabelecer uma posição crítica em relação às lutas sociais contemporâneas, teorizar o lugar da cultura no capitalismo e pensar padrões de Justiça.

Nancy Fraser, já era uma autora de prestígio internacional quando lançou seu texto até agora mais influente e discutido: "From Redistribution to Recognition? Dilemmas of Justice in a Postsocialist Age"3, onde chama-

\footnotetext{
${ }^{1}$ Este ensaio reproduz, com algumas alterações, o capítulo 6 de minha tese de doutorado $A$ Sociologia Política do Reconhecimento: as contribuições de Charles Taylor, Axel Honnethe Nancy Fraser.

2 FRASER, Nancy e HONNETH, Axel. Redistribution or Recognition? A political-philo sophical exchange. London/ New York: Verso, 2003.
} 
va atenção para o impacto das questões de reconhecimento sobre a estratégia de movimentos sociais particulares. Sua tese central era a associação da temática do reconhecimento apenas às lutas "culturais" por proteção à identidade grupal, levando à necessidade da problematização simultânea das questões redistributivas, pensadas pela autora num registro "material", localizado no âmbito da economia política, por oposição à cultura. Fraser foi duramente criticada pelo esquematismo do seu argumento ${ }^{4}$, o que a levou a várias reformulações, algumas delas levadas a cabo no contexto de seu debate com Axel Honneth, o outro principal formulador original, além de Taylor, no campo da "teoria crítica do reconhecimento".

\section{DILEMAS DA ERA PÓS-SOCIALISTA}

Fraser defende que as demandas por reconhecimento são relativamente recentes na sociedade contemporânea. $\mathrm{Na}$ verdade, elas fariam parte de um processo de evolução da sociedade capitalista denominado por ela como "era pós-socialista". O que caracteriza esse processo, como o nome mesmo já diz, é uma nova configuração da ordem mundial globalizada e multicultural, na qual as lutas por redistribuição são paulatinamente substituídas por reconhecimento, ou seja, os conflitos de classe são tendencialmente suplantados por conflitos de status social, advindos da dominação cultural. Fraser parece concordar parcialmente com o diagnóstico do cientista político Ronald Inglehart de que vivemos atualmente uma revolução silenciosa, na qual há uma decrescente ênfase em valores materiais, relacionados à economia-política, em favor de valores "pós-materiais" 5 .

${ }^{3}$ Este artigo compõe um dos capítulos do livro de Fraser Justice Interruptus. Critical reflec tions on the "Postsocialist" condiction. New York: Routledge, 1997. E foi publicado em português "Da Redistribuição ao Reconhecimento? Dilemas da Justiça na Era Pós-Socialista," in: SOUZA, Jessé (org.) Democracia Hoje: novos desafios para a teoria democrática contem porânea. Brasília: Ed. UnB, 2001, p. 245-282.

4 Ver especialmente o texto de Iris Young “Unruly Categories: A Critique of Nancy Fraser's dual Systems Theory"in: New Left Review, 222, (March/April, 1997) p. 147-160.

5 Inglehart, em seu livro Modernization and Posmodernization: cultural, economic and polit ical change in 43 societes, afirma que houve uma mudança enorme na cultura política nos últimos tempos. Segundo ele, a partir da Segunda Guerra Mundial, com o estabelecimento do Estado de Bem-Estar social, com o advento das novas tecnologias, com a educação maciça e de boa qualidade acessível a todos houve mudanças importantes nos valores em todas as esferas: política, economia, em relação ao trabalho, à família, ao comportamento sexual, dentre outras. Essas mudanças teriam proporcionado um progresso social que permitiu a superação de necessidades básicas através de políticas distributivas e que, atualmente, as 
Acredito que Fraser concordaria parcialmente com este diagnóstico na medida em que ela, assim como Inglehart, localiza a mudança da redistribuição para o reconhecimento a partir das novas demandas dos movimentos sociais. Contudo, em oposição a ele, Fraser não crê que os dilemas da redistribuição tenham sido resolvidos nos países centrais, ao contrário, o que ela denuncia é um crescimento das desigualdades sociais na maioria dos países do mundo, inclusive em países centrais como Estados Unidos.

O que preocupa Fraser é a desconexão entre as duas dimensões dos conflitos sociais, a dimensão econômica e a cultural, que estão normalmente associadas. $\mathrm{O}$ que ela percebe nas novas demandas dos movimentos sociais por reconhecimento de identidades culturais é precisamente a minimização e não-tematização das questões referentes às desigualdades econômicas, numa ordem social globalizada e marcada por injustiças econômicas. A separação entre as dimensões econômica e cultural é falsa na visão dela. O desafio então é descobrir como conceitualizar reconhecimento cultural e igualdade social de maneira que uma demanda não enfraqueça a outra. Significa também teorizar sobre os modos pelos quais as desvantagens econômicas e o desrespeito cultural estão entrelaçados e apoiados um no outro.

Um primeiro esforço nesse sentido foi feito por ela em seu texto, já mencionado, "Da redistribuição ao reconhecimento? Dilemas da justiça na era pós-socialista". Nesse texto, Fraser constrói tipos ideais de conflitos sociais com o intuito de mostrar a inter-relação entre as demandas por redistribuição e por reconhecimento através da análise dos possíveis remédios adotados para vencer injustiças sociais específicas. Seu intuito é conceitualizar reconhecimento cultural e igualdade social de forma que ambos se sustentem e não se enfraqueçam mutuamente. Sendo assim, ela se propõe a esboçar alguns esquemas de análise que permitam conciliar essas duas demandas. Para isso, ela toma como exemplos emblemáticos as lutas por questões de gênero e raça.

Inicialmente, são feitas as distinções analíticas dos dois tipos de reivindicações. Vale ressaltar novamente que essas distinções são apenas analíticas, uma vez que ela acredita que a injustiça econômica está ligada

sociedades contemporâneas, ou melhor, os países centrais, estariam vivenciando uma mudança na cultura política que comportaria lutas por em relação às identidades culturais e étnicas, em defesa do meio ambiente etc. Estas se caracterizariam pelo seu conteúdo não material, seriam lutas que não têm por fim a redistribuição de renda. INGLEHART, Ronald. Modernization and Postmodernization: cultural, economic and political change in 43 soci eties. Princeton: Princeton Universtiy Press, 1997. 
à injustiça cultural e vice-versa. As reivindicações por redistribuição enfatizam que a injustiça socioeconômica está enraizada na estrutura políticoeconômica. Como exemplos desse tipo de exploração temos a exploração do trabalho, a marginalização econômica (ser limitado a trabalho indesejável ou de baixa remuneração) e privação (ter negado um padrão material de vida adequado) ${ }^{6}$. Já as lutas para vencer as injustiças culturais se dirigem a busca de soluções para a destruição de padrões sociais de comportamento e interpretação tidos como consensos cristalizados permeados por preconceitos. Como exemplos de dominação cultural temos o nãoreconhecimento de práticas representacionais, comunicativas e interpretativas de uma cultura, o desrespeito através da esteriotipação de representações públicas nas práticas cotidianas, a criação de mitos de igualdade de participação e expressão, entre outros.

Os remédios para solucionar esses problemas parecem, em alguns casos, contraditórios. O remédio para a injustiça econômica diz respeito a algum tipo de mudança na estrutura política-econômica. Como medidas para isso, pode-se pensar na redistribuição de renda, numa reorganização do trabalho, na sujeição de investimentos à tomada de decisões democráticas etc. O remédio para a injustiça cultural ${ }^{7}$, por sua vez, implica algum tipo de mudança cultural como, por exemplo, reavaliação positiva de identidades discriminadas e estereotipadas, bem como dos produtos culturais de grupos marginalizados; valorização da diversidade cultural, ou ainda, a desconstrução e transformação dos padrões societais de representação, interpretação e comunicação para permitir uma maior possibilidade de auto-interpretação para os membros da comunidade política. A análise das lutas de gênero e raça pode ilustrar bem como esses remédios podem ser contraditórios, já que esses grupos sofrem tanto de injustiça econômica quanto de injustiça cultural.

No caso das lutas envolvendo questões de gênero e raça tem-se que afirmar tanto o princípio da igualdade quanto o da diferença. $\mathrm{O}$ movimento feminista teve de lutar para desconstruir a injustiça econômica através da denúncia de que o gênero estrutura a divisão fundamental entre trabalho produtivo e assalariado e trabalho reprodutivos, doméstico e não-assalariado, típico de mulher. Além disso, o gênero também estrutura a divisão de trabalho entre ocupações profissionais e bem pagas dominadas por homens e o

6 FRASER, Nancy, "Da redistribuição ao reconhecimento? Dilemas da Justiça na Era PósSocialista" p.252.

7 Idem, ibidem, p. 252. 
trabalho doméstico, mal pago, dominado por mulheres. Como solução para isso, a transformação da economia-política deveria eliminar a exploração, a marginalização e a privação específica do gênero, o que significa eliminar as diferenças de gênero, a especificidade do gênero.

Se a questão do gênero envolvesse somente isso, estaria resolvida. Contudo, gênero não é só uma diferenciação baseada na políticaeconômica, mas também em padrões culturais. Isso é, existe uma especificidade em ser mulher que não deveria ser subsumida a um padrão cultural que privilegia as práticas, as formas de comunicação e interpretação masculinas $^{8}$. Para combater a injustiça cultural é necessária uma desconstrução do androcentrismo (padrões culturais que privilegiam as características da masculinidade) que caminha junto com o sexismo cultural (a desvalorização e depreciação de coisas vistas como "femininas" tomadas como emotivas e irracionais). A solução aqui está baseada na afirmação das diferenças de gênero, na valorização das práticas ligadas ao feminino.

A mesma coisa ocorre com o movimento negro. De um lado, o movimento negro deve lutar contra a divisão do trabalho assalariado entre ocupações mal pagas, domésticas, corporais ocupadas pelas pessoas de cor e, as ocupações técnicas, administrativas e bem pagas ocupadas pelas pessoas brancas. Por outro lado, o movimento negro deve lutar contra o eurocentrismo e enfatizar a especificidade da cultura negra.

Como se pode perceber os remédios parecem contraditórios, uma vez que devem enfatizar, ao mesmo tempo, a igualdade e a diferença. Como alternativa a dilemas desse tipo, Fraser analisa as estratégias, chamadas por ela, de afirmação ou de transformação. Para vencer os dilemas entre redistribuição e reconhecimento, pode-se adotar medidas afirmativas ou transformativas. As medidas afirmativas têm por objetivo a correção de resultados indesejados sem mexer na estrutura que os forma. Já os remédios transformativos têm por fim a correção dos resultados indesejados pela reestruturação da estrutura que os produz. ${ }^{9}$

8 Iris Young é uma das autoras que denuncia os perigos da absolutização das formas de comunicação baseadas no discurso racional, não-emotivo e distanciado, tidas como características típicas do universo masculino. YOUNG, Íris. "Comunicação e o outro: além da democracia deliberativa", In: Democracia Hoje, p. 365-386.

9 Tomemos como exemplo a questão das desigualdades econômicas. Remédios afirmativos tendem a enfatizar medidas de transferência de renda através de programas de seguro social, de assistência pública etc. Longe de abolir as diferenças de classe, esses remédios as suportam e as modelam, deixando intacta a estrutura que produz as desvantagens de classe. Além disso, tendem a criar uma estilização do grupo "favorecido" como sendo inferior por não conseguirem por si mesmos uma situação favorável de vida, colocando, assim, em xeque a con- 
A partir da construção de esboços que caracterizam os remédios afirmativos e transformativos, Fraser propõe saídas para a questão do gênero. Ela salienta que as dimensões econômica e cultural estão interligadas e reforçando-se mutuamente, porque desvantagens sexistas e androcêntricas estão institucionalizadas na economia, da mesma forma que as desvantagens econômicas impedem a participação igual na esfera da cultura, tanto no cotidiano como nas esferas públicas. Como a utilização de remédios afirmativos para vencer as injustiças econômicas tende a rotular as mulheres como deficientes e insaciáveis, com o tempo as mulheres podem ser vistas como privilegiadas, alvo de tratamento especial e benefícios injustos.

Como remédio eficaz para as lutas de gênero, ela propõe a combinação entre redistribuição transformativa e reconhecimento transformativo. Isso implica a adoção de uma espécie de feminismo socialista ${ }^{10}$ e na desconstrução feminista guiada pelo desmantelamento do androcentrismo por meio da desestabilização das dicotomias de gênero. A meta a longo prazo é a substituição de hierarquias de gênero por redes de diferença mútuas. Isso não significa que essa estratégia não tenha problemas, no entanto, a desconstrução do androcentrismo permite uma releitura das diferenças de gênero na esfera do trabalho, permitindo se pensar em uma sociedade onde é possível a construção de novas identidades e diferenças que são livremente elaboradas e desconstruídas com base na igualdade social. Isso evitaria também as chamas do ressentimento.

cepção universalista do igual valor das pessoas. Remédios transformativos, ao contrário, combinam programas universalistas de bem-estar social, impostos progressivos, políticas macroeconômicas voltadas para a criação do emprego e tomadas de decisões democráticas sobre prioridades macroeconômicas. A tendência é, portanto, a minar a diferença de classes. Os remédios afirmativos podem ter um efeito perverso na promoção da diferenciação entre classes, estigmatizando a diferença, somando o insulto da falta de reconhecimento à injúria da privação. A redistribuição transformativa, em contraste, pode promover a solidariedade e ajudar a rever formas de não-reconhecimento. FRASER, op. cit., p. 270-271.

10 Quando fala em socialismo, Fraser reconhece que existem, atualmente, umas séries de problemas associadas com o socialismo. Hoje ninguém continua a defender uma economia controlada na qual haja pouco espaço para o mercado. Tampouco há concordância sobre o lugar e a extensão da propriedade pública numa sociedade socialista. Ela não discute o conteúdo preciso da idéia socialista, apenas objetiva invoca-la por ser uma perspectiva que permite pensar em alternativas para reparar as injustiças redistributivas pela profunda reestruturação da ordem política-econômica. FRASER, op. cit., p. 269. O socialismo é um exemplo da estratégia transformativa, uma vez que seu objetivo é a mudança da estrutura. Apesar da falência dos regimes socialistas ser evidente, isso não significa que é um erro se pensar na reestruturação da economia. Essa idéia ainda faz muito sentido se contrastada com a redistribuição afirmativa que deixa intocadas as causas da má-distribuição. 


\section{O DUALISMO DE PERSPECTIVA DE FRASER}

Foram recuperados os principais pontos desse texto para mostrar como Fraser procura desenvolver, a partir dessas idéias seminais, uma teoria social que não só permita fundamentar sua concepção de justiça social, mas também que ilumine os debates políticos. Até então, Fraser havia tentado mostrar a partir de exemplos de lutas de movimentos sociais tanto o surgimento das lutas por reconhecimento como suas ambigüidades. A análise foi feita de maneira pragmática pelo exame da realidade empírica. Em seu último trabalho, recém-publicado, Redistribution or Recognition? A PoliticalPhilosophical Exchange, ela recupera os insights da análise empírica para construir sua teoria social, agregando as dimensões filosófica e política.

A questão central do livro é: como entender melhor a relação entre redistribuição e reconhecimento? Aqui surge a primeira e mais importante diferença entre Fraser e Honneth. Este advoga que todos os conflitos sociais têm como natureza primária a luta por reconhecimento. Mais adiante será recuperada a teoria de Honneth a fim de esclarecer essas diferenças. Fraser acredita que Honneth tenha subsumido as lutas por distribuição de renda ao reconhecimento. Diferentemente dele, ela irá propor uma perspectiva dualista de análise dos conflitos sociais com o objetivo de pensar um conceito de justiça social que agregue essas duas dimensões, possibilitando, assim, uma teorização da cultura no capitalismo contemporâneo.

A discussão filosófica do tema do reconhecimento é balizada essencialmente pelo debate entre duas tradições de pensamento, a kantiana e a hegeliana. A questão que baliza esse debate diz respeito ao entendimento desses autores em relação às fontes da moralidade. Kant constrói os pressupostos da razão fundamentados na idéia de que a característica central dos seres humanos é possuírem um potencial comum de racionalidade. A partir disso, ele criou os pressupostos da razão prática, no qual as ações são justificadas e validadas pelo seu caráter universalista. Explicando melhor, qualquer sujeito moral agiria tendencialmente do mesmo modo, pela generalização do imperativo moral obtido a partir do seu monólogo interior. Assim, exercer a minha liberdade até o limite da liberdade alheia - na realidade um refraseamento da conhecida máxima cristã - seria algo que qualquer pessoa de posse da razão elementar poderia fazer. Existem imperativos da razão que comandam as ações humanas e que estariam internalizados no sujeito moral. ${ }^{11}$

11 Neokantianos como Habermas expandem o monólogo original para um diálogo efetivo, materializado no discurso moral. 
Hegel, ao contrário, defende que a circunstância primordial do sujeito moral é a de que ele está, desde sempre, "situado" dentro de um contexto ético maior que o define, em grande medida, também como ator moral. A teoria do reconhecimento desenvolvida por ele, como vimos no começo deste trabalho, tem por objetivo exatamente mostrar que todo processo de interação é constituído pelo reconhecimento mútuo e que todos os conflitos estão baseados na violação desse consenso que fundamenta acordos intersubjetivos. A evolução dos indivíduos e da sociedade se dá na medida em que esse reconhecimento se amplia e permite novas formas de individuação e inclusão social que serão discutidas pela teoria de Honneth. O que é importante é marcarmos a diferenciação entre eles. Para Kant, a fonte da moralidade é o monólogo do sujeito consigo mesmo, as ações baseadas nos imperativos da razão. Já, para Hegel, a fonte da moralidade são os acordos intersubjetivos baseados no reconhecimento mútuo, que estão em constante transformação, uma vez que a sociedade e os indivíduos evoluem a cada nova etapa de reconhecimento.

Está-se brevemente discutindo essas distinções, porque elas irão marcar as diferenças entre Fraser e Honneth. Honneth seguindo a tradição hegeliana defende que o reconhecimento intersubjetivo é condição para o desenvolvimento de uma identidade positiva necessária para a participação na esfera pública. Segundo ele, existe sempre uma concepção de boa vida baseada em critérios normativos que está por trás das lutas por reconhecimento.

Fraser, ao contrário de Honneth, deseja enxergar o reconhecimento não como uma categoria central da Sociologia e Psicologia Moral baseada na idéia de que reconhecimento está ligado à auto-realização individual, mas, sim, como uma questão essencialmente de justiça. Seguindo a tradição kantiana, ela quer mostrar que a categoria do reconhecimento pode ser melhor explicada de acordo com um padrão universal de justiça, aceito por todos, a partir do pressuposto de igual valor do ser humano. Logo, não-reconhecimento para ela é analisado menos em relação às atitudes depreciatórias sofridas pelos indivíduos, mas mais pela análise de práticas discriminatórias institucionalizadas. ${ }^{12}$

Para ela, é possível fundar um padrão de justiça com base na idéia de participação paritária. “(...) that is, to desintitutionalize patterns of cultural value that impede parity of participation and to replace them with patterns that foster it."13 As vantagens da análise do reconhecimento como

12 FRASER e HONNETH, op. cit., p. 29.

13 Idem, ibidem, p. 30. 
sendo um critério de justiça ao invés de auto-realização permitiria justificar as lutas como moralmente obrigatórias em condições modernas de pluralismo, deixando os componentes da auto-realização e do valor ético de práticas num segundo plano, sendo, portanto, de fácil justificação. O método adotado aqui é o deontológico. A participação paritária pode ser reconhecida como sendo o principal objetivo da teoria da justiça, podendo ser facilmente justificada de acordo com os critérios universalistas da razão.

Fraser crê que seja bem mais difícil a justificação da necessidade de reconhecimento a partir da idéia de auto-realização desenvolvida por Honneth.

When claims for recognition are premised on a psychological theory of "the intersubjective conditions for undistorted identity formation", as Honneth's model, they are made vulnerable to the vicissitudes os that theory; their moral bindingness evaporates in case the theory turns out to be false. By treating recognition as a matter of status, in contrast, the model I am proposing avoids mortgaing normative claims to matters of psychological fact. One can show that a society whose institutionalized norms impede parity of participation is morally indefensible whether or not they distort the subjectivity of the oppressed. ${ }^{14}$

Na verdade, o que garante a moralidade, para Fraser, é o procedimento, a garantia da participação paritária na vida cotidiana e na esfera pública. Todos possuem direitos iguais a ter estima social como uma condição de oportunidades iguais. Enquanto na formulação de Honneth, estima social está entre as condições de intersubjetividade não distorcidas para a formação de uma identidade positiva. Moralidade significa, para ele, o estabelecimento de critérios normativos já reconhecidos intersubjetivamente, não no contexto da "discussão paritária" de Fraser (que lembra fortemente os pressupostos do discurso moral habermasiano), mas no âmbito da própria vida cotidiana onde todos participam.

Uma outra vantagem da construção do não-reconhecimento como sendo uma violação de justiça é que ela facilitaria a integração de lutas por reconhecimento com lutas por redistribuição de recursos e riquezas, já que não trataria as demandas por reconhecimento como questões éticas.

14 FRASER e HONNETH, op. cit., p. 32. 
On the self-realization view, in contrast, the prospects for their conceptual integration are dim. That approach, as we saw, treats recognition as an ethical question, which makes it incommensurable with distributive justice. As a result, whoever wishes to endorse both redistribution and recognition seems to risk philosophical schizophrenia. ${ }^{15}$

Para discutir as principais questões da teoria social e entender as relações entre má-distribuição e não-reconhecimento na sociedade contemporânea, Fraser utiliza dois conceitos centrais da teoria sociológica - os conceitos de classe e status social. ${ }^{16}$ A questão aqui é: como se vinculam as relações teóricas entre estrutura de classe e ordem de status no capitalismo globalizado? Os termos classe e status denotam ordens de subordinação ligadas e legitimadas socialmente. Dizer que a sociedade possui uma estrutura de classes é dizer que ela institucionaliza mecanismos econômicos que sistematicamente negam a alguns de seus membros oportunidades necessárias para que eles participem junto com os outros da vida social. Ao passo que uma estrutura que cria hierarquias de status institucionaliza padrões de cultura que negam a alguns de seus membros o reconhecimento necessário para que eles participem da vida social.

O prestígio social é derivado então de uma ordem intersubjetiva que reconhece que determinados membros contribuem de forma diferenciada para a reprodução da vida social. Portanto, estruturas de classe e de sta tus social constituem obstáculos para a participação paritária, representando supostamente distintas ordens de subordinação. Apesar de representarem analiticamente distintas ordens de subordinação, em geral, a injustiça advinda do não-reconhecimento é acompanhada pela má-distribuição e vice-versa.

Normalmente são distinguidas as dimensões das lutas sociais e essas dimensões são associadas aos diferentes aspectos da ordem social, isto é, à subordinação de status e à subordinação de classe. Essa dicotomia

15 Idem, ibidem, p. 33.

16 Os dois conceitos, classe e status social, são discutidos por Marx e Weber. Diferentemente de Marx, Fraser não se preocupa com o conceito de classe a partir dos mecanismos de exploração presentes na divisão do trabalho, uma vez que isso não pode ser resolvido através do reconhecimento e da redistribuição, mas tão-somente por meio da abolição de classes. A ênfase dada por ela recai sob suas conseqüências normativas da divisão de classes que impedem a participação paritária. . "In my conception, rather, class is an order of objective subordination derived from economic arrangements that deny some actors the means and resources they need for participatory parity." FRASER, op. cit., p. 48. 
permite mostrar, segundo Fraser, as dificuldades de integração entre as duas dimensões que estão associadas. Ela faz a distinção apenas analítica das duas dimensões para propor uma análise dualista da perspectiva dessas dimensões, conforme podemos ver na seguinte passagem:

As we shall see, economic ordering is typically institutionalized in markets; cultural ordering may work through a variety of different institutions, including kindship, religion, and law. In all societies economic ordering and cultural ordering are mutually imbricated. ${ }^{17}$

Fraser procura construir a sua teoria social para deixar evidente que as injustiças de status estão relacionadas com a estrutura moderna do capitalismo e não desapareceram com a mudança da sociedade tradicional para a sociedade moderna, apenas se modificam os padrões que fundam o status social. Na sociedade tradicional, o conceito de status social era expresso pelo ideal de honra. Numa sociedade estática como a tradicional, o ideal de honra era derivado essencialmente dos papéis sociais. Isso não significa dizer que atualmente não o seja, o que mudou na sociedade moderna foi a estrutura dos papéis sociais, da ordem cultural. Na sociedade tradicional, a ordem cultural era indiferenciada, eticamente monista e caracterizada pela inexistência de qualquer horizonte alternativo de cultura.

Nenhuma dessas condições está presente na sociedade moderna. A ordem cultural de nossa sociedade não está mais restrita a um grupo, a família, como era na sociedade tradicional. Graças à cultura de massa, às migrações e às esferas públicas transnacionais hoje é difícil dizer onde termina uma cultura e começa outra; todas as culturas são internamente híbridas. Há uma multiplicidade de arenas de ação que propagam padrões diferenciados de valores culturais, a ordem da sociedade é eticamente plural, há uma diversidade de valores, que permite a contestação constante de horizontes e padrões de valores. Há também uma contestação da hierarquia de status social

Finally, status hierarchy is illegitimate in modern society. The most basic principle of legitimacy in this society is liberal equality, as expressed both in market ideals, such as equal exchange, the career open to talents, and meritocratic competition, and in democratic ideals, such as equal citizenship and status equality. Status hierarchy violates all these ideals. ${ }^{18}$

17 FRASER e HONNETH, op. cit., p. 50.

18 Idem, ibidem, p. 55. 
Fraser pensa que seja possível eliminar os padrões que hierarquizam na sociedade moderna pela continuação de um processo histórico iniciado há mais de dois séculos de transformação qualitativa da sociedade. Dois grandes processos contribuíram para modernizar o status de subordinação da sociedade moderna, o mercado e o crescimento de uma sociedade civil plural.

A lógica do mercado que propaga a idéia de não ser regulada por padrões de valores culturais, mas, sim, governada por padrões de maximização dos ganhos pelos imperativos do auto-interesse. O mercado introduz uma quebra na ordem cultural tradicional. O que Fraser ressalta é que o mercado, no entanto, coexiste com uma ordem valorativa. Ele não destrói ou dissolve simplesmente as distinções de $s$ t a t $u s$, ao contrário, ele as instrumentaliza para servirem aos fins da eficiência propagada pelo mercado.

O crescimento de uma sociedade civil plural permitiu uma ampliação enorme dos padrões culturais que regulamentam as diferentes arenas de ação social. Como resultado, tem-se a constituição de uma ordem eticamente plural na qual os padrões e horizontes de valores são bem mais contestados e estão abertos a mudanças. Há a diferenciação de amplas instituições não-mercadológicas que adquirem algum tipo de autonomia e desenvolvem cada uma delas padrões de valores culturais que regulamentam o processo de interação.

A denúncia de Fraser é a de que as abordagens que se propõem a analisar a realidade social contemporânea tendem a subsumir as duas dimensões dos conflitos sociais uma na outra. O economicismo, por exemplo, tende a propagar a idéia de que a solução para os problemas da realidade social pode ser dada pela economia. São aquelas explicações que afirmam, por exemplo, que se o PIB de tal país crescer tanto por cento é possível que se reduza a pobreza, se distribua renda etc. Segundo essa abordagem, a cultura é um epifenômeno da Economia. Há outra corrente chamada de Culturalista ${ }^{19}$ que, ao contrário do economicismo, propõe que mudanças na cultura são capazes de gerar mudanças em toda ordem social, transformando a economia num epifenômeno da cultura.

Existe, ainda, um grupo denominado de pós-estruturalistas, ao qual pertenceriam Iris Young e Judith Butler, que rejeitam as distinções entre a ordem econômica e a ordem cultural. Os pós-estruturalistas dizem

${ }^{19}$ Fraser acha que Honneh tem uma leitura culturalista. "I mean a monistic social theory that holds that political economy is reducible to culture and that class is reducible to status. As I read him, Axel Honneth subscribes to such a theory."FRASER e HONNETH, op. cit., p. 105. 
que economia e cultura estão tão relacionadas que não se pode distinguilas. Advogam, portanto, a desconstrução da distinção, simplesmente por defenderem que todas as lutas são simultaneamente econômicas e culturais. O problema dessa abordagem, segundo Fraser, é que, por não realizarem a distinção entre os aspectos econômicos e culturais, os pósestruturalistas não são capazes de resolver questões onde essas dimensões parecem se contradizer nas lutas sociais. Um bom exemplo disso, são as lutas de gênero e raça.

Por não acreditar que seja possível analisar os conflitos sociais isolando as duas dimensões, a proposta de Fraser é a utilização de um dualismo de perspectiva (perspectival dualism) que permite avaliar analiticamente as demandas por reconhecimento e por redistribuição. Ela insiste que a separação é apenas analítica, uma vez que esses domínios (economia e cultura) estão totalmente conectados. Economia e cultura não pertencem a domínios societários distintos. As abordagens feitas pelo mainstream multiculturalism deixam intocadas as estruturas de classe que estão por trás do não-reconhecimento de minorias. ${ }^{20}$ "On the contrary, misrecognition and maldistribution are so complexly interwined today that each must be grasped from a larger, integrated perspective that also encompasses the other. Only when status and class are considered in tandem, in sum, can our current political dissociations be overcome." 21

O dualismo de perspectiva também não resolve o problema de como conectar esses domínios, sua vantagem, no entanto, seria deixar evidente o sintoma do problema, permitindo a distinção entre as demandas é possível analisar a relação entre os diferentes domínios. Além disso, o dualismo de perspectiva evita a redução de um domínio no outro, evitando a dicotomia entre cultura e economia que obscurece a visualização da interrelação entre elas. 22

Agora se colocam as questões de natureza política, isso é, que acordos institucionais podem assegurar as condições de objetivas e intersubjetivas para a paridade participativa? Que políticas e reformas podem realizar a tarefa de combater simultaneamente a desigualdade e o nãoreconhecimento? Que orientação político-programática pode satisfazer as lutas por redistribuição e reconhecimento, minimizando as possibilidades de redução de um domínio no outro?

20 FRASER e HONNETH, op. cit., p. 74.

${ }^{21}$ Idem, ibidem, p. 66.

22 FRASER e HONNETH, op. cit., p. 63. 
Reconhecendo que os argumentos teóricos são introduzidos nos debates públicos, Fraser pensa que as considerações contextuais podem e devem servir de material para o desenvolvimento da teoria. A teoria pode informar se as categorias de política e os programas são compatíveis com os requerimentos da justiça, porém a questão da ponderação de escolhas é sempre uma questão política. O objetivo da autora é clarificar os parâmetros para o debate público.

Como os acordos políticos devem ter como fim remover os impedimentos para a participação paritária, Fraser retoma a análise feita em seu texto "Da redistribuição ao reconhecimento?", mostrando a diferença entre os remédios afirmativos e os transformativos e a vantagem desses últimos. Ela afirma também que a distinção entre afirmação e transformação é sempre contextual e não absoluta. Cabendo, portanto, a cada movimento social mostrar como são afetados pelos dois tipos de injustiças e propor medidas transformativas.

\section{O MONISMO MORAL DE HONNETH}

Honneth, ao contrário de Fraser, não acredita que seja suficiente para a construção de uma teoria social pensar a teoria do reconhecimento a partir tão-somente da análise dos novos movimentos sociais. Isso se justifica, segundo ele, por várias razões. Ele pensa que Fraser, ao caracterizar os novos movimentos sociais pela multiplicidade de esforços organizados politicamente de reconhecimento de seu próprio estilo de vida, adota uma perspectiva de supergeneralização da experiência americana (over-generalization of american experiences). Isso porque esse tipo de luta teve apenas um papel secundário em países como a França, Inglaterra e Alemanha, onde os problemas "tradicionais" relacionados à política do trabalho, do bem-estar social se desenvolvem de forma bastante forte.

Honneth acredita que para afirmarmos que os conflitos contemporâneos são lutas por reconhecimento cultural é necessário, antes de tudo, averiguar quais são as formas morais relevantes de privação e sofrimento. Para fundamentar essa necessidade, ele relembra o que disse Bourdieu em La misère du monde. Nesse livro, Bourdieu diz que alguns problemas de miséria não são conhecidos publicamente como formas relevantes de conflito social. Portanto, para se obter uma perspectiva geral de formas típicas de sofrimento fundadas socialmente numa 
sociedade capitalista é fundamental ir além das problematizações feitas na esfera pública, incorporando as difusas expectativas e esperanças dos cidadãos. $^{23}$

É necessário se pensar em um critério normativo abstrato para a realização da análise dos conflitos sociais contemporâneos. Se, é falso, para Honneth, o ponto de partida de Fraser ao tomar os movimentos sociais, não ter um critério abstrato de mensuração das formas de sofrimento e privação é outro erro cometido por Fraser. A teoria social que se orienta ao redor das demandas perceptíveis dos movimentos sociais tem como conseqüência não conseguir abordar fatores fundamentais da análise. Um desses fatores, é que Fraser, assim como Taylor, superestima a capacidade das sociedades ocidentais de terem homogeneizado o princípio da dignidade ligado à concepção de universalização dos direitos, de percepção de todos os indivíduos como iguais, como um fim em si mesmos. Ao fazer isso, eles removem todos os elementos presentes nas lutas políticas por identidade dos conflitos legais do passado

What is presently salient are the historical stylizations and simplifications contributing to this linear chronology: on the one hand, for instance, we find an a priori absence of the legal realm from Taylor's notion of contemporary struggles for recognition; on the other hand and inversely, all cultural elements related to "identity politics" are removed from legal conflicts of the past. ${ }^{24}$

Para Honneth, todas as demandas por justiça distributiva podem ser melhor explicadas com ajuda de categorias normativas que emergem da teoria do reconhecimento. Ao contrário de Fraser, ele defende que todos conflitos sociais têm como base uma luta por reconhecimento. Honneth 25 propõe a utilização de categorias explicativas da teoria do reconhecimento desenvolvida por ele, a partir da teoria do reconhecimento de Hegel, para analisar as demandas dos conflitos sociais contemporâneos.

23 "To live up to that role, they would need to first expand their narrow notion of "politics", salvaged as it has been from bygone days, and not only offer an opening to the publicly announced demands of different social movements with, for instance, ecological, anti-racist, and feminist orientation, but also incorporate the diffuse expectations and hopes of (ordinary)citizens." FRASER e HONNETH, op. cit., p. 119.

24 FRASER e HONNETH, op. cit., p. 123.

25 Ver HONNETH, Axel. The Struggle for Recognition: The Moral Grammar of Social Conflicts. Cambridge/Massachusetts: The MIT Press, 1996. 
Sua primeira indagação diz respeito ao entendimento preliminar das possíveis formas de sofrimento social. Os estudos de teoria sociológica carecem, segundo Honneth, de uma análise que ressalte a natureza normativa da moral. Falta à perspectiva marxista, por exemplo, uma hipótese que considere as causas potenciais do senso de injustiça. "Marxism, then, the leaning toward utilitarian anthropology allows granting collective interest to a social class, the antithetical position lacks any concepts for forming hypotheses regarding the potential causes of the sense of social injustice." 26

Habermas 27 é um dos poucos autores que se dedicou ao estudo da natureza normativa da moral. O procedimentalismo habermasiano está baseado na idéia de que os indivíduos obedecem à lei porque esta representa as aspirações e os consensos acordados no mundo da vida, ou seja, está vinculada a um código moral baseado num entendimento intersubjetivo. Falta, porém, ao procedimentalismo habermasiano à análise da relação entre o processo de interação social e a formação das identidades individuais, baseada numa teoria da subjetividade. Só com a ligação entre esses dois campos é possível auferir qual é a substância dos acordos morais, o que é considerado bem para a sociedade.

Honneth toma os estudos feitos por Thompson ${ }^{28}$ e Moore 29 sobre as lutas de classe na Inglaterra do século XIX. Esses autores chegaram à conclusão de que o conteúdo das lutas do século XIX não era essencialmente por distribuição de renda, mas sim pelo reconhecimento de que expectativas intersubjetivas não foram consideradas ou cumpridas. Sendo assim, todas as lutas por distribuição representam uma luta por reconhecimento de acordos firmados intersubjetivamente e que possuem validade normativa. É o não-reconhecimento que está na base dos sentimentos de sofrimento, humilhação e privação. "What is called for is a fundamental conceptual shift to the normative premises of a recognition-theory locating the core of all experience of injustice in the denial of social recognition, in the phenomena of humiliation and contempt." 30

26 Idem, ibidem, p. 124.

27 HABERMAS, Jürgen. Direito e democracia: entre facticidade e validade I e II. Rio de Janeiro: Ed. Tempo Brasileiro, 1997.

28 THOMPSON, Edward P. Customs in Common: Studies in Traditional Popular Culture. New York, 1993.

29 MOORE, Barrington. Injustice: The Social Basis of Obedience and Revolt. New York, 1978.

30 FRASER e HONNETH. Redistribution or Recognition? , p. 130. 
Agora se pode perceber o ponto central de discordância entre Fraser e Honneth. Este não concorda com a separação feita por ela entre demandas por reconhecimento e demandas por redistribuição para que se possa entender a conexão entre cultura e economia no capitalismo. Essa dicotomia entre as lutas suprime ou negligencia as lutas por reconhecimento presentes em todos os conflitos por igualdade legal. Para que possamos entender a especificidade do capitalismo contemporâneo, bem como a interrelação entre as injustiças culturais e as econômicas, é fundamental uma análise da gramática moral que está por trás de todos os conflitos sociais.

Este tema do reconhecimento legal dificilmente poderia ser enfatizado em excesso. Ele marca para Honneth uma espécie de divisão interna ocorrida dentro da categoria de honra, na passagem à sociedade moderna, terminando por constituir uma dualidade que assume a forma de duas fontes paralelas e concorrentes de reconhecimento: a legal, baseada na igualdade legal-formal, e a de status ou apreciação social, ligada à valorização religiosa do trabalho profissional. No primeiro sentido, a noção hierárquica de honra é democratizada; no segundo ela é "meritocracizada", na medida que dependente da contribuição individual em quanto "cidadão trabalhador".

Seria precisamente essa dimensão de princípios embutidos na realidade social que permitiria o caráter de racionalidade e de necessidade de justificação pública às formas de reconhecimento mútuo. Fraser desconheceria esse caráter de pressuposto ao imaginar uma esfera "material" como núcleo do tema da distribuição. Um complicador para uma percepção adequada da especificidade de cada uma das pressuposições em jogo na luta por reconhecimento é certo "imperialismo expansivo" da dimensão legal. A regulação tende a se implantar desde as relações intrafamiliares, a esfera por excelência da autoconfiança, até a dimensão do "princípio do desempenho", a qual passa a ser cuidadosamente separada de garantias legais tornadas "direitos sociais", ou seja, a construção de uma zona social apartada das considerações de desempenho, característico das instituições do welfare state. ${ }^{31}$

Para Honneth, nenhuma análise sobre "distribuição" deve desconsiderar a incorporação parcial pelo "welfare state" do recurso "estima social". Para esse autor, esse processo talvez possa ser adequadamente compreendido como um avanço do princípio do igual tratamento legal independentemente ou às custas da noção de desempenho diferencial, o 
que, aliás, é uma excelente prova histórica da eficácia social do poder de persuasão baseado em razões morais justificáveis. A partir de então uma certa porção menor dos recursos sociais passa a ser distribuído sob o princípio de direitos sociais, enquanto uma porção maior continua sob a égide do princípio do desempenho (a única justificativa para a desigualdade capitalista).

Toda a dinâmica da luta pelo reconhecimento, para Honneth, parte da relação entre não-reconhecimento e posterior reconhecimento legal. Posto de outro modo: toda luta por reconhecimento dá-se por uma dialética do geral e do particular. Afinal, é sempre uma particularidade relativa, uma "diferença" que não gozava de proteção legal anteriormente que passa a pretender tal status. Esses conflitos, no entanto, são percebidos num sentido completamente pré-político. É nesse sentido que Honneth, contra Fraser, imagina uma experiência de "desrespeito" como estando na base de todo conflito social (como Taylor). Também nesse sentido, Honneth recusa a pecha de "monismo culturalista" e assume um "monismo moral", desde que as instituições centrais do capitalismo são dependentes de legitimação racionalmente motivada permanecendo, portanto, dependente de consenso moral. Contra Fraser, Honneth critica a ausência de qualquer explicação adequada que possa legitimar o perspectivismo dualista de Fraser. Onde estaria este dualismo relacionado com a reprodução social das sociedades capitalistas modernas? Faltaria a Fraser qualquer indício de uma teoria social alternativa que pudesse apoiar sua teoria dos conflitos políticos.

\section{CONCLUINDO}

O debate entre Fraser e Honneth comprova que a teoria do reconhecimento está ainda começando, apesar de sua crescente influência nos debates filosóficos, sociológicos e políticos de nosso tempo. Minha posição pessoal em relação a esse debate se inclina a assumir uma posição mais próxima de Honneth do que de Fraser. Fraser parece, efetivamente, separar de forma indevida "economia" de "cultura" como se fosse possível alguma forma econômica que não estivesse, em toda a sua extensão, perpassada por valores. Apesar da autora assumir que existe uma eficácia valorativa também nos fatos econômicos de redistribuição, ela jamais chega a reconstruir teoricamente, o modo e o como essa mesma eficácia se realizaria. 
Quando Honneth critica a ausência de uma teoria sociológica que possa dar conta das elaborações de Fraser, acho que este autor tem em mente precisamente esse tipo de imprecisão. Fraser, na realidade, parece indecisa em assumir uma postura habermasiana conseqüente, o que explicaria, por exemplo, tanto sua reificação sistêmica da Economia, por um lado, quanto seu conceito procedural de Justiça, por outro. Por outro lado, a autora pretende ao mesmo tempo se alinhar com pontos de vista que pressupõem uma noção mais substantiva de "eticidade", ao pressupor a existência de consensos opacos comandando formas importantes da formação de identidades individuais e grupais. Para ela, no entanto, por algum motivo obscuro, que também desconserta Honneth, esse tipo de consenso só existiria numa esfera "cultural" em sentido estrito. O que Honneth chama de "monismo moral", de forma muito semelhante ao que Taylor denomina de "hierarquia moral" subjacente as idéias e práticas sociais concretas do Ocidente, seria, precisamente a tese fundamental de que toda ação humana, seja em contextos econômicos, políticos ou culturais em sentido estrito, está desde sempre inserida numa moldura, ainda que opaca e inarticulada, que pressupõe escolhas e avaliações morais como sua causa última.

A postura de Fraser equivale a retirar da perspectiva teórica do reconhecimento precisamente seu principal mérito, que é haver contribuído para re-significar tudo aquilo que o alto capitalismo em sua atual fase de triunfalismo sem oposição tem tornado crescentemente naturalizado, muito especialmente na ordem econômica. De qualquer modo, a postura de Fraser também é importante na medida em que atenta para a necessidade de se levar em consideração como questões concretas e candentes, as quais, por isso mesmo, lograram transformar-se em movimentos sociais com voz própria, devem ser analisados pragmaticamente em suas vicissitudes estratégicas de luta política. A tentativa de manter acesa a chama da relação entre teoria e prática concreta parece ser seu mérito principal.

PATRÍCIA MATTOS é professora da Universidade Cândido Mendes. 